\title{
Everyday Life of the Russian Rural Society and Factors of Its Depopulation
}

\author{
Evgeny Reutov ${ }^{1},{ }^{*}$ Valentin Babintsev ${ }^{1}$, Victor Zakharov ${ }^{1}$, Marina Reutova ${ }^{1}$ \\ ${ }^{1}$ Belgorod National Research University, Russia \\ "Email: reutovevg@mail.ru
}

\begin{abstract}
Based on the results of the sociological researches, it is stated that traditional relations and values are preserved in rural communities of central Russia with emerging trends of their transformation in the direction of mass culture. The factors of depopulation of rural society are revealed: the outflow of young people and the aging of the population, the lack of jobs and the low level of development of small and micro-businesses, the lack of social infrastructure. At the same time, the prospects are noted, due to the COVID-19 pandemic and the more complex epidemiological situation in large cities, the outflow of part of the urban population to the suburbs and rural areas. This process can potentially significantly increase the attractiveness of rural areas for living, contribute to their human development. However, this does not remove the threat of economic and cultural pressure on rural areas from cities and the loss of their attractiveness to young people. Among the mechanisms for the preservation and development of rural societies, the continuation of the digitalization of jobs and the promotion of remote employment, as well as public and private investments in the transport network, regional and local economies, and social protection are suggested.
\end{abstract}

Keywords: Rural society, Rural communities, Depopulation, Traditionalism, Migration.

\section{INTRODUCTION}

The demographic development of modern Russia is a complex process in which quite contradictory trends coexist and replace each other. Since the early 1990s, the depopulation has been the dominant trend - a decline in the population due to a decrease in the birth rate and an increase in mortality. In 1992-2011, the natural population decline in Russia was 13.5 million people, and the birth rate at the lowest point in 1999 was 1.157 [1, pp.32-34]. According to L.L. Rybakovskiy's assessment, the negative long-term demographic trends were superimposed on the mass socio-economic maladaptation of the population, caused by the destruction of a number of social institutions, the usual way of life and entailed supermortality, refusal to give birth to children and emigration abroad [4].

By the mid-2010s, the depopulation in Russian society was suspended - both as a result of the entry into reproductive age in the early 2000s of a relatively large generation of the 1980s, and as a result of measures taken by the President and the Government of Russia aimed at supporting the birth rate (the so-called maternity capital).

However, the positive effect did not last long, and since 2017, the Russian society has again been characterized by a steady excess of mortality over birth rate, which in the conditions of economic stagnation could no longer be compensated by the migration influx.

The process of urbanization in Russia has led not only to a steady increase in the share of the urban population and its predominance over the rural one, but also to the normativity of the so called "urban" way of life, including in the reproductive behavior of the population. It is characterized by an increase in the age of marriage, a predominant focus on a small family, and the erosion of the value of the rural lifestyle. As a result, rural society has ceased to play the role of a demographic reserve and a source of maintaining the demographic balance of the Russian society. As evidenced by the results of the researches of D. Santiago-Alarcon, I. MacGregor-Fors, similar processes occur with even greater intensity in European countries, in most of which the process of 
urbanization is superimposed on a decrease in the birth rate [11], as well as - in recent decades - in China, which is reflected in the works of Geng Lin, P. Liu, H. Ubels, G.A. Wilson et al. [7,9,12,13].

Currently, the rural communities in Russia, as well as regions in general, are highly differentiated in their socioeconomic conditions. Ethnocultural characteristics of the regions are also of great importance for the reproduction of demographic potential. However, for the vast majority of regional rural societies in Russia, it is the process of depopulation that is more or less relevant due to the excess of mortality over birth rate and migration outflow to cities. So, V. Erokhin, W. Heijman, A. Ivolga among the most common threats to sustainable rural development are unemployment and depopulation, which makes it practical to diversify traditional sources of income in rural areas through tourism and other alternative activities [6]. And if the first factor of depopulation is formed as a result of the interweaving of long-term demographic, socio-cultural trends and the nature of the social situation, then the migration outflow is based primarily on the population's dissatisfaction with the quality of life in rural areas and opportunities for professional and career self-realization. At the same time, according to the results of a number of studies, the COVID-19 pandemic contributes to increasing the attractiveness of rural areas as a permanent or temporary residence. So, I.E. Kalabikhina predicts mass or partial deurbanization - the outflow of the population of cities concerned with the problem of epidemiological safety, to the suburbs or even to the countryside [8]. According to D. Santiago-Alarcon, I. MacGregor-Fors, the pandemic has only exacerbated research interest in epidemiological highly urbanized social systems in the case of the degradation mechanisms of urban management and sanitation urban institutions [11]

\section{RESEARCH METHODOLOGY}

The purpose of the article is to describe, based on the results of an empirical study, the main parameters of everyday life of rural society in Russia, as well as to identify a set of factors that contribute to its depopulation. The empirical basis of the article is the results of focus group interviews conducted in October 2019 in four municipalities of the Belgorod Region within the framework of the study "Consolidation of rural communities" (total number of participants - 53 people, age range - 18-68 years, gender composition - 41 women and 12 men), a series of semi-formalized interviews (September-October 2019, N=50 respondents, Belgorod and Voronezh regions) and data from an expert survey (50 experts representing the Belgorod, Voronezh and Kursk regions were interviewed, June-July 2020), conducted in in the framework of the study "Mental inequalities as a factor of social polarization of the Russian province").

\section{RESULTS DISCUSSION}

The analysis of the statements of the participants of focus group interviews allows us to build a generalized model of rural society in a fairly prosperous socioeconomic region of Russia and, nevertheless, including a set of factors of real or potential depopulation.

Many rural communities now retain their characteristics of relatively closed neighbor communities with a high level of cohesion, tight social control and developed practices of mutual assistance. This is especially true for villages located at a distance from major cities. The residents of such villages, as a rule, personally know most of their fellow villagers, very often aware of the subtleties of their family ties, character traits, place of work and other status and personal characteristics. They are willing to help their fellow villagers in difficult life situations, as well as in the framework of everyday economic and household practices, and also willingly participate in collective festive events that are regularly held by local administrations, and collective labor activities related to the improvement of the village. During focus group interviews, their participants repeatedly spoke not only about the regularity of such events and their social benefits, but also about the mass and voluntary nature of their participation in them: "When we have events, concerts - we always have a full hall", "We will go today, we will talk to you and go to a subbotnik", "Subbotniks are every Thursday, we clean up the cemetery".

The principal feature of rural communities is the value significance and high intensity of neighborhood relations. Members of the local neighborhood community are the most significant source of psychological, labor and material support for many villagers. Among the leading types of neighborly mutual assistance, the study participants included:

- material, labor and other assistance in emergency situations: "We had a fire..." There was a lot of help from the neighbors especially", "If the funeral - the neighbors will come to help»;

- everyday routine resource exchanges: "Take bread, salt", "Someone has more potatoes, someone has less, the neighbor will always share"; " My husband helps all the neighbors to repair cars, cut wood";

- psychological support: "He came, drank tea already good. Psychological assistance";

- delivery of goods, payment of utilities: "Pensioners often ask to pay for utilities", "They come to me and ask me to bring medicines. I will never say no. And then I will ask them for milk, and they will not refuse me either. And not just me, we all live like this"; 
- child care and housekeeping: "Look after the house. It often happens", "To look after the children - this is not even discussed";

- assistance to disabled residents of the village: "There are elderly people, their estate is overgrown. The farmer sent the equipment", "I have elderly neighbors. We live with them as one family. We help them, they help us. Help remove a large heavy pan from the stove, sit with the child»;

- professional services on a free basis: "I have come to the aid of my neighbors a thousand times over these months. I am a nurse in the outpatient clinic. I've been on vacation for the last two weeks, but I don't sit at home, I go home, I get injections. Free of charge, of course."

Developed practices of mutual assistance and joint activities are a powerful factor of collective identity and have a positive impact on the social well-being of representatives of rural society. Thanks to them, rural residents, even with an objective lack of social resources and insufficient efficiency of social institutions, do not experience a sense of frustration and social exclusion. The results of studies conducted in a number of regions of Russia and Ukraine, in particular by J. Round, C. Williams, show that informal economic practices are crucial for many households that employ a wide range of survival tactics. In addition, these tactics rely on a high level of social capital, ensuring that households are more likely to stay in their current place than migrate to cheaper regions [10].

However, considering rural communities as a kind of enclaves of traditionalism, it is necessary to make two significant reservations. First, rural communities located near major cities are gradually transforming in the direction of urbanizing the way of life and consciousness of their inhabitants. Such rural communities are characterized by a high level of pendulum migration many of their residents, and sometimes the vast majority of the working-age population, work in urban industrial enterprises and minimize traditional work on the land. The limited number of jobs also forces many residents of those villages that are located far from major cities and industrial enterprises of the region to leave for work. Only this time the directions of labor migration are megacities - Moscow, Voronezh, Krasnodar. Accordingly, the terms of separation from the native village are also increasing: "Many are leaving. To Moscow, Voronezh, Krasnodar region for construction", "There are no normally paid jobs. Yes, and work poultry workers and pigsties' workers, and there the work is hard, and the salary is small." The separation of labor activity from the rural area significantly contributes to the socio-cultural and psychological separation from the local community. Relations between people in such rural communities become more atomized and formal.
Secondly, even in rural communities that retain traditional features, an intergenerational gap is fixed. Thus, the migration of young people from rural areas is typical for all agricultural regions of Russia. Emigration, unwillingness to work in agriculture and the aging of farmers and farm managers are serious problems that raise questions about who will work in agriculture in the future. The restoration or expansion of relations between agricultural schools and agricultural enterprises, access to credit for starting businesses and buying agricultural land, and improved living conditions in rural municipalities may encourage young people with agricultural education to stay in rural areas and work in agriculture [5].

The participants of the focus groups regretfully say that young people no longer want to maintain traditional relations for rural societies and prefer communication in social networks to direct communication: "Children will be different, life is different and they are different. We are still of the old times, the old leaven". The value of being in a rural society with a high level of psychological comfort, but limited opportunities for self-realization and mobility for young people is significantly reduced relative to the older generation. Based on this, migration sentiments among young people are much more pronounced. Their feature is also a kind of "singlevector". If the adult villagers, leaving to work, usually come back; come in the village and who left before the elderly - to live in "the small homeland", the young people left to study, as a rule, have not returned "The young people leave, and try to go to the region, not to stay in the village. They leave to study and live, they build and stay there", "Young people leave because there is no work, and the one that is there is low-paid", "Are your children determined to leave in the future or stay here? Of course they're leaving. What is the reason? There is no work". The outflow of young people is noted by residents of almost all villages, with the exception of suburbia - in them this problem is not so acute, but even here in the mood of young people there is a focus on self-realization in large cities, including outside the region.

The migration outflow of young people by the villagers themselves is estimated as the most important factor of depopulation: "There are fewer people. Young people do not stay, they go to study and do not return." The outflow of young people is superimposed on the decline in the birth rate, especially manifested in remote areas: "Few children", "Few young people, few children, low birth rate".

The questions raised during the semi-formal interviews about the possibility of realizing life chances and achieving life success in the place of their residence revealed the predominance of extremely skeptical ideas about the appropriate conditions in rural areas compared to large cities. "Not everyone finds a job that they like. It is better to go somewhere. We do not have a job"; 
"Elsewhere. You can not do it with us"; "We have very few jobs."

At the same time, the participants of the interview broadcast the corresponding settings to their children: "And what would you like more - that your child (children) remained to live in your city (village) or went to another place? - It is also a matter of choice. But I would like to invite my children to try their hand in a larger locality, whether it is a regional center, the capital, maybe. When you are young, you need to set more ambitious goals."

In addition to the actual demographic factors that have a direct impact on the processes of depopulation (outgoing youth mobility and aging of rural society), in most rural communities there are a number of indirect, but no less significant social factors that reduce the attractiveness of rural life. These include: the low level of income of rural residents compared to the urban population, the lack of jobs and the low level of development of small and micro-businesses, the lack of social infrastructure and, above all, health care facilities, and the low level of medical care.

The problems of low incomes and limited employment opportunities can be overcome or minimized by running a personal subsidiary farm, organizing a micro- or small business. It is also possible to improve the rural area and make it comfortable for living by means of self-organization of residents with minimal help from the authorities. However, it is impossible to organize high-quality medical care on your own. Thus, the life expectancy of the urban population of Russia at the end of 2018 was 73.34 years, rural -71.67 years (the difference is small, but stable for the last two decades) [3]. Participants in the focus groups repeatedly noted certain problems in the organization of medical care, despite the fact that the region was a large-scale reform of the health system, in which rural recreated actually lost previously primary care facilities - on-site obstetric units formed general practitioners' offices.

Thus, according to the balance of optimism/pessimism, the statements of participants of rural communities during individual and group interviews can be divided into two blocks. The first block includes an assessment of current relations within rural society and general social well-being. Positive assessments and moderate optimism dominate here: people are generally satisfied with their relations with their neighbors, demonstrate a high level of involvement in collective actions, and are generally satisfied with the way of life they lead (with the exception of the limited labor market and obvious failures in the activities of health care institutions). But at the same time, the participants of rural society talk about a number of problems that, accumulating, create a cumulative effect. The second set of assessments is based on extrapolating these problems into the future. And here, with a few exceptions, social pessimism prevails. Residents of villages speak about intergenerational cultural gaps, about the lack of rural social infrastructure (educational, medical, partly leisure) for self-realization of the socially and economically active part of the population - first of all, young people. As a result, most of the study participants, without using this term itself, actually talk about depopulation and the threat of degradation of the human capital of rural communities as a result of the outflow of the youngest and most active part of the population.

The expert assessment carried out for the purpose of objectification of ideas about the situation in rural communities and verification of spontaneous public assessments revealed a significant inequality of life chances in the increment of human capital (primarily in the educational and professional spheres). On the basis of previously conducted researches with the participation of the authors of the studies we can say that inequality in life chances acutely conscious of the Russian provinces as to the economic and cultural "center" - Moscow and St. Petersburg, and within provincial society - between the villages and small towns, on the one hand, and regional centers, on the other. The narrowness of labor markets, low wages in most sectors of regional economies, and often the dominance of nepotism and other manifestations of cronyism, on the one hand, preserve the traditionalist values of most residents of the Russian province, on the other hand, they form dissatisfaction with the social situation and push the most ambitious people out of provincial societies [2].

From the point of view of experts, the territorialsettlement feature has a significant impact on the possibility of obtaining a high-quality education. Thus, the chance of getting a high-quality education of an average resident of a village is estimated by experts at 4 points on a 10-point scale, a small city - at 5.16 points, a provincial regional center - at 7.3 points, a megalopolis - at 9 points. So, the gap between the chances of obtaining a quality education between the extreme settlement groups was more than doubled (fig. 1).

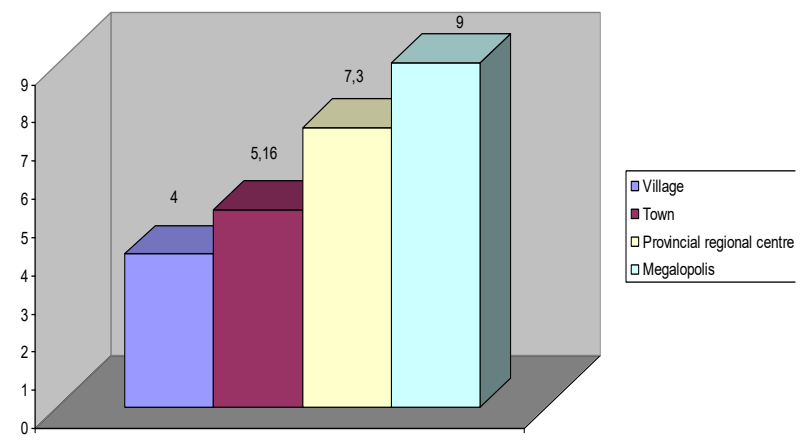

Figure 1 The possibility of obtaining a quality education, $\%$ and average score. 
The difference in the chances of a successful career is similar. According to the expert assessment, a resident of the village has its possibility equal to 3.82 points (on a 10 -point scale), a resident of a small city -5.02 points, a provincial regional center -6.8 points, a megalopolis 8.06 points. There is also a more than two-fold difference in the expert assessment of the chances between the extreme settlement groups (fig. 2)

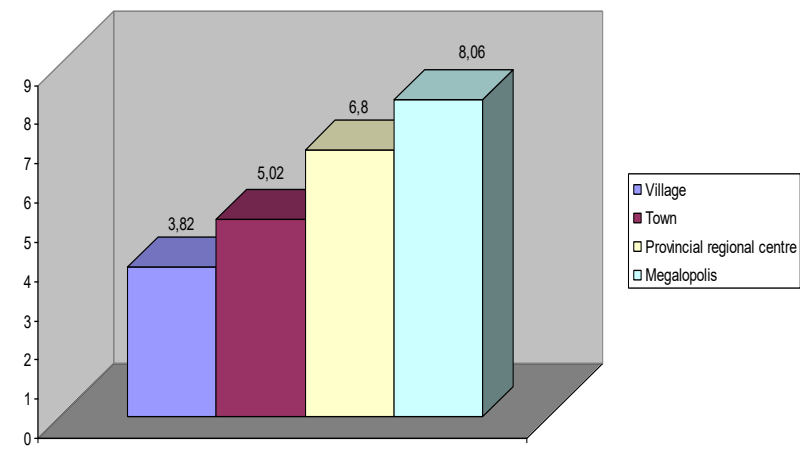

Figure 2 Career opportunities, \% and average score.

\section{CONCLUSIONS}

Thus, in addition to the ongoing depopulation of rural areas, in the context of pandemic COVID-19, the reverse process is also possible, i.e. the outflow portion of the urban population, as a result of a more complicated epidemiological situation and degradation mechanisms of urban management, in suburbia and countryside. This process can potentially significantly increase the attractiveness of rural areas for living, contribute to their human development. However, it would be clearly premature to make predictions about the reversal of the migration flow in Russia from the city to the countryside. Indeed, this process has been going on for quite a long time, but, as a rule, within urban agglomerations. As a result, single-story satellite neighborhoods are formed around cities that have nothing in common with rural communities, except for private households. Traditional rural communities continue to experience economic and cultural pressures from cities and lose their appeal to the younger part of the population. Perhaps the digitalization of jobs and remote employment can partly resolve the dilemma between the comfort of a place of residence and a high-paying and prestigious job. However, public and private investments in the transport network, regional and local economies, and social protection are more effective mechanisms for preserving and developing rural societies. In this case, there is a chance for the survival of local societies that perform an important social function of spatial stabilization and maintaining the territorial unity of the country in Russia.

\section{ACKNOWLEDGMENTS}

The study was carried out within the framework of the state task of the National Research University
"BelSU" for 2020, project No. 0624-2020-0027 "Sociodemographic determinants of rural development of the Central Chernozem Economic Region".

\section{REFERENCES}

[1] A. Aganbegyan, Overcoming depopulation in Russia: for the first time in 20 years, the birth rate has equaled the death rate, Economic strategies Vol. 15 Iss. 2(110) (2013) 32-34 (In Russ.).

[2] E.V. Reutov, M.N. Reutova, I.V. Shavyrina, Life success and the chances of achieving it in the views of residents of the Russian province, Sociological Research 6 (2020) 61-71. DOI: https://doi.org/10.31857/S013216250009480-1 (In Russ.).

[3] Russian statistical yearbook. Retrieved from: https://rosstat.gov.ru/bgd/regl/b19_13/Main.htm (In Russ.).

[4] 1.1. Rybakovsky Factors of depopulation in Russia, Population 3(61) (2013) 4-19 (In Russ.).

[5] Z. Bednaříková, M Bavorová., E.V. Ponkinac, Migration motivation of agriculturally educated rural youth: The case of Russian Siberia, Jornal of Rural Studies Vol. 45 (2016) 99-111. DOI: https://doi.org/10.1016/j.jrurstud.2016.03.006

[6] V. Erokhin, W. Heijman, A. Ivolga Sustainable Rural Development in Russia Through Diversification: The Case of the Stavropol Region, Visegrad Journal on Bioeconomy and Sustainable Development, Vol. 3, Iss. 1, 2014. Retrieved from: https://content.sciendo.com/configurable/contentpa ge/journals $\$ 002$ fvjbsd $\$ 002 f 3$ \$002f1\$002farticlep20.xml?tab body=pdf-78589

[7] Geng Lin, Xiaoru Xie, Zuyi Lv Taobao practices, everyday life and emerging hybrid rurality in contemporary China, Journal of Rural Studies Vol. 47 part B (2016) 514-523. DOI: https://doi.org/10.1016/j.jrurstud.2016.05.012

[8] I.E. Kalabikhina, Demographic and social issues of the pandemic, Population and Economics 4(2) (2020) 103-122.

DOI: https://doi.org/10.3897/popecon.4.e53891

[9] P. Liu, Ye Zhao, N. Ravenscroft, Harder M.K. Responsibility-driven collective action in the context of rapid rural depopulation, Journal of Rural Studies, April Iss. 75 (2020) 48-56. DOI: https://doi.org/10.1016/j.jrurstud.2020.02.008

[10] J. Round, C. Williams Coping with the social costs of 'transition': Everyday life in post-Soviet Russia and Ukraine, European Urban and Regional Studies 
Vol. 17 Iss. 2 (2010) 183-196. DOI: http://dx.doi.org/10.2139/ssrn.2289927

[11] D. Santiago-Alarcon, I. MacGregor-Fors Cities and pandemics: urban areas are ground zero for the transmission of emerging human infectious diseases, Journal of Urban Ecology Vol. 6 Iss. 1 (2020) 1-3.

DOI: https://doi.org/10.1093/jue/juaa012

[12] H. Ubels, T. Haartsen, B. Bock Social innovation and community-focussed civic initiatives in the context of rural depopulation: For everybody by everybody? Project Ulrum 2034, Journal of Rural Studies, March 2019, pp. 1-11. DOI: https://doi.org/10.1016/j.jrurstud.2019.02.019Get rights and content

[13] G.A. Wilson, Z. Hu, S. Rahman Community resilience in rural China: The case of $\mathrm{Hu}$ Village, Sichuan Province, Journal of Rural Studies 75 (2018) 130-140.

DOI: http://dx.doi.org/10.1016/j.jrurstud.2018.03.016 